Polymer Journal, Vol. 38, No. 11, pp. 1182-1188 (2006)

(C) 2006 The Society of Polymer Science, Japan

\title{
Chitinase-Catalyzed Copolymerization to a Chitin Derivative Having Glucosamine Unit in Controlled Proportion
}

\author{
Akira Makino, Masashi OHMAE, and Shiro KoBAYASHI ${ }^{\dagger, \dagger \dagger}$ \\ Department of Material Chemistry, Graduate School of Engineering, Kyoto University, \\ Nishikyo-ku, Kyoto 615-8510, Japan
}

(Received July 7, 2006; Accepted August 28, 2006; Published October 19, 2006)

\begin{abstract}
Chitinase-catalyzed copolymerization of an $N, N^{\prime}$-diacetylchitobiose oxazoline monomer (1) with an $N$-acetylchitobiose oxazoline monomer (2) has been investigated. Catalysis of chitinase derived from Bacillus sp. showed close polymerizability of these two comonomers, giving rise to the corresponding copolymer. The degree of $\mathrm{N}$-deacetylation (DDAc) of the product was controlled by varying the comonomer feed ratio. In contrast, catalysis of chitinase from Serratia marcescens showed different reactivity of the comonomers. Thus, homopolymerization of monomer 2 was preferentially occurred at the beginning of the reaction and copolymer was hardly obtained. [doi:10.1295/polymj.PJ2006075]

KEY WORDS Enzymatic Copolymerization / Chitin / Chitinase / Chitobiose Oxazoline Derivative / Transition State Analogue Substrate / Degree of $N$-deacetylation /
\end{abstract}

Chitin is a naturally occurring polysaccharide composed of $\beta(1 \rightarrow 4)$-linked 2-acetamido-2-deoxy-D-glucopyranose (GlcNAc), which is abundantly distributed in invertebrates and fungi. ${ }^{1}$ Chitosan is a well-known bioactive polymer of 2-amino-2-deoxy-D-glucopyranose $(\mathrm{GlcN})$ connecting in a $\beta(1 \rightarrow 4)$ fashion. ${ }^{2}$ These polysaccharides exhibit a variety of physiological activities such as antimicrobial, ${ }^{3}$ anti-tumor ${ }^{4}$ and wound-healing activities ${ }^{5}$ in addition to the excellent nature of biocompatibility and biodegradability. Furthermore, oligosaccharides of chitin and chitosan also show many biological activities such as antioxidant and immuno-stimulatory effect. ${ }^{6}$ Therefore, chitin, chitosan and their oligomers has been frequently employed in medicine, ${ }^{7}$ pharmaceutics, ${ }^{8}$ and materials chemistry. ${ }^{9}$

Biosynthesis of chitin is performed by the catalysis of chitin synthase (EC 2.4.1.16) with uridine-5'diphospho-GlcNAc (UDP-GlcNAc) as a substrate. ${ }^{10}$ Chitosan is produced industrially by alkaline hydrolysis of natural chitin. ${ }^{11}$ Some fungi have chitosan in their cell walls, ${ }^{2}$ which is biologically synthesized by the tandem actions of chitin synthase and chitin deacetylase, catalyzing $\mathrm{N}$-deacetylation of chitin to generate GlcN units. ${ }^{12}$ In either case, chitosan has discrete structures resulting from incompletion of $N$ deacetylation, leading to the structural diversity. The bioactivities of chitin and chitosan depend on the basicity of the polymers, that is, on the number of GlcN units incorporated in a polymer chain; for instance, with increase of the degree of $N$-deacetylation
(DDAc), the immuno-adjuvant activity increases markedly. ${ }^{13}$ Chitin and chitosan samples with controlled DDAc are, therefore, essential to understand the structure-activity relationships at a molecular level. Thus, tailored synthesis of chitin and chitosan is a key technology for the development of chitin- and chitosan-based biomaterials.

For these two decades, we have been investigating enzymatic polymerization, which enabled the in vitro synthesis of natural and unnatural polysaccharides with precisely controlled structure. ${ }^{14}$ Synthetic chitin was prepared via chitinase-catalyzed ring-opening polyaddition of an $N, N^{\prime}$-diacetylchitobiose [GlcNAc$\beta(1 \rightarrow 4)$ GlcNAc] oxazoline derivative (1) as a transition-state analogue substrate (TSAS) monomer. ${ }^{15}$ The polymer produced has a perfect structure consisting of $\beta(1 \rightarrow 4)$-linked GlcNAc, that is, the DDAc is $0 \%{ }^{16}$ Furthermore, synthesis of a chitin-chitosan hybrid polysaccharide via chitinase-catalyzed ring-opening polyaddition was archieved. ${ }^{17}$ The TSAS monomer employed is an $N$-acetylchitobiose [GlcN $\beta(1 \rightarrow 4)$ GlcNAc] oxazoline derivative (2), which has an amino group at the non-reducing saccharide unit. The hybrid has an alternating structure of $\beta(1 \rightarrow 4)$-linked GlcN and GlcNAc, whose DDAc is $50 \%$. These results motivated us to synthesize a chitin derivative with controlled DDAc via copolymerization of monomers 1 and 2 catalyzed by chitinase (Scheme 1). The present paper provides a novel method for the tailormade synthesis of a chitin derivative with controlled DDAc ranging from $0 \%$ to $50 \%$.

\footnotetext{
${ }^{\dagger}$ To whom correspondence should be addressed (Tel/Fax: +81-75-724-7688, E-mail: kobayash@kit.ac.jp).

${ }^{\dagger \dagger}$ Present address: $R \&$ D Center for Bio-based Materials, Kyoto Institute of Technology, Sakyo-ku, Kyoto, 606-8585, Japan
} 

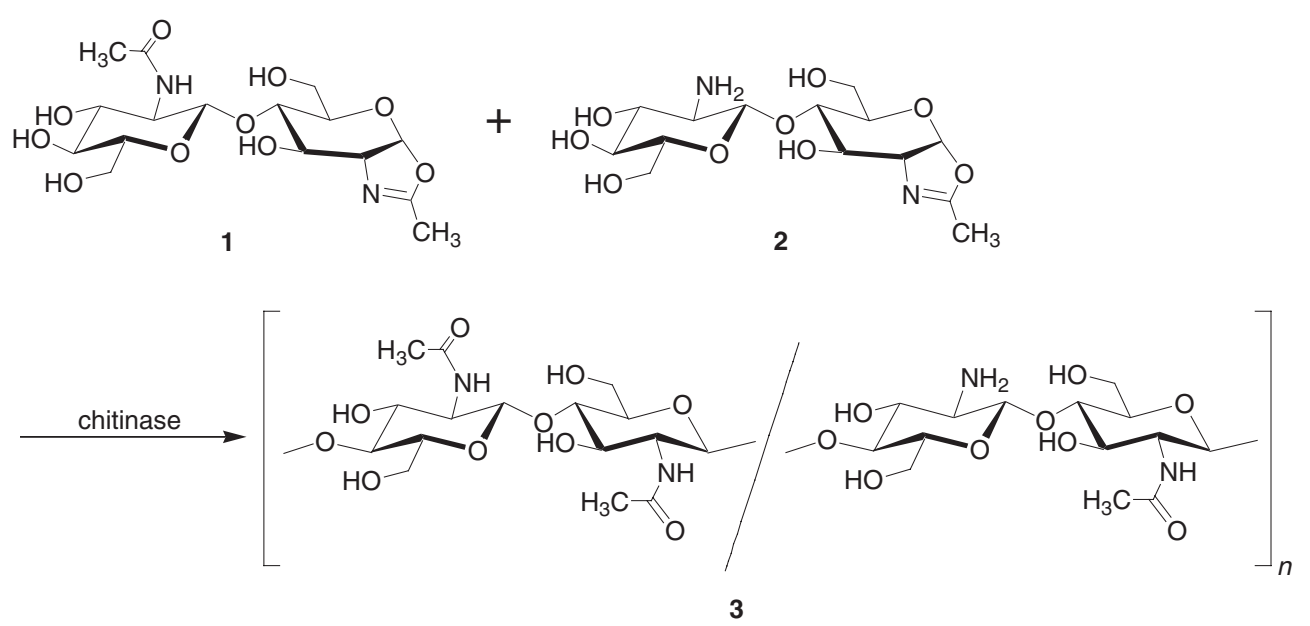

Scheme 1. Chitinase-catalyzed copolymerization of $\mathbf{1}$ and $\mathbf{2}$.

\section{EXPERIMENTAL}

\section{Materials}

Comonomers $\mathbf{1}$ and $\mathbf{2}$ were synthesized as previously published. ${ }^{15,17}$ Chitinases from Bacillus sp. and from Serratia marcescens were purchased from Wako Pure Chemicals Inc. (Lot No. LDH7046) and from Sigma (Lot No. 45H4117), respectively. Both enzymes were used without further purification. Di$N$-acetylchitobiose, tetra- $N$-acetylchitotetraose, and hexa- $N$-acetylchitohexaose were purchased from Seikagaku Corp. (Lot Nos. 9612020, 9812110, and 9812110, respectively) and were used as chitooligosaccharide standards. Dimer, tetramer, and hexamer of GlcN were purchased from Seikagaku Corp. (Lot Nos. 9710130, 0210100 and 0309160, respectively) and used as chitosanoligosaccharide standards. Pullulan standards $\left(M_{\mathrm{w}}=5900,11800\right.$, and 22800; Lot No. 80301) were purchased from Showa Denko K.K.

\section{Measurement}

NMR spectra were recorded with a Bruker DPX400 spectrometer. All assignments were based on COSY experiments. Concentrations of each comonomer during the reaction was determined by high-performance liquid chromatography (HPLC) measurements using Tosoh LC8020 system with combination of Chemco ODS-W column $(4.6 \times 250 \mathrm{~mm})$ eluting with distilled water-acetonitrile $(98: 2, \mathrm{v} / \mathrm{v}$; flow rate, $1.00 \mathrm{~mL} / \mathrm{min} ; 30^{\circ} \mathrm{C}$ ) and Shodex Asahipak NH2P-50 4E (amino) column $(4.6 \times 250 \mathrm{~mm})$ eluting with distilled water-acetonitrile $(3: 7, \mathrm{v} / \mathrm{v}$; flow rate, $0.5 \mathrm{~mL} / \mathrm{min} ; 40^{\circ} \mathrm{C}$ ). The concentration of comonomer 2 was measured by amino column. The concentration of $\mathbf{1}$ was calculated by deducting that of $\mathbf{2}$ from the total comonomer concentration, which is determined by ODS column. Yields and molecular weights of the product 3 were determined by size exclusion chromatography (SEC) measurements using Tosoh GPC8020 system with Tosoh TSK-gel $\alpha$-3000 column $(7.8 \times$ $300 \mathrm{~mm}$ ) eluting with $0.6 \mathrm{M} \mathrm{LiCl}$ in $N$-methyl-2-pyrrolidone (NMP) $N, N$-dimethylacetamide (DMAc) mixture $\left(2: 1, \mathrm{v} / \mathrm{v}\right.$; flow rate, $\left.0.6 \mathrm{~mL} / \mathrm{min} ; 40^{\circ} \mathrm{C}\right)$. The water-insoluble product was dissolved in $1.2 \mathrm{M}$ $\mathrm{LiCl}$ in NMP-DMAc $(2: 1, \mathrm{v} / \mathrm{v})$ mixed solution. Calibration curve for the GPC measurements was drawn by dimer, tetramer and hexamer of GlcNAc $\left(M_{\mathrm{n}}=424,831\right.$ and 1237), dimer, tetramer and hexamer of GlcN $\left(M_{\mathrm{n}}=413,808\right.$ and 1204), and pullulan $\left(M_{\mathrm{n}}=5900,11800\right.$, and 22800) as standard materials. Matrix-assisted laser desorption ionization time-offlight mass spectrometry (MALDI-TOF MS) analysis was performed with a Jeol JMS-ELITE spectrometer using 2,5-dihydroxybenzoic acid as the matrix under positive ion mode. IR spectra were recorded on a Perkin-Elmer Spectrum One spectrometer.

Enzymatic Copolymerization of $\mathbf{1}$ and $\mathbf{2}$ Catalyzed by Chitinase from Bacillus $s p$.

A typical procedure of copolymerization is given as follows: Comonomers $\mathbf{1}(2.0 \mathrm{mg}, 0.0050 \mathrm{mmol})$ and $\mathbf{2}$ $(1.8 \mathrm{mg}, 0.0050 \mathrm{mmol})$ were mixed and dissolved in a phosphate buffer $(50 \mathrm{mM}, \mathrm{pH} 8.5,80 \mu \mathrm{L})$. To the solution was added chitinase from Bacillus sp. $(0.20 \mathrm{mg})$ dissolved in a phosphate buffer $(50 \mathrm{mM}, \mathrm{pH} 8.5$, $20 \mu \mathrm{L}$ ). The reaction mixture was kept standing at $10^{\circ} \mathrm{C}$. An aliquot $(3 \mu \mathrm{L})$ of the mixture was sampled at the appropriate time for monitoring the concentration changes of comonomers by HPLC. At the time that the consumption of either comonomer was completed $(1.5 \mathrm{~h})$, the mixture was heated at $90^{\circ} \mathrm{C}$ for 10 min to inactivate the enzyme. Because white precipitate was produced during the polymerization, it was separated by centrifugation. The supernatant containing a water-soluble part of the product $\mathbf{3}$ was 

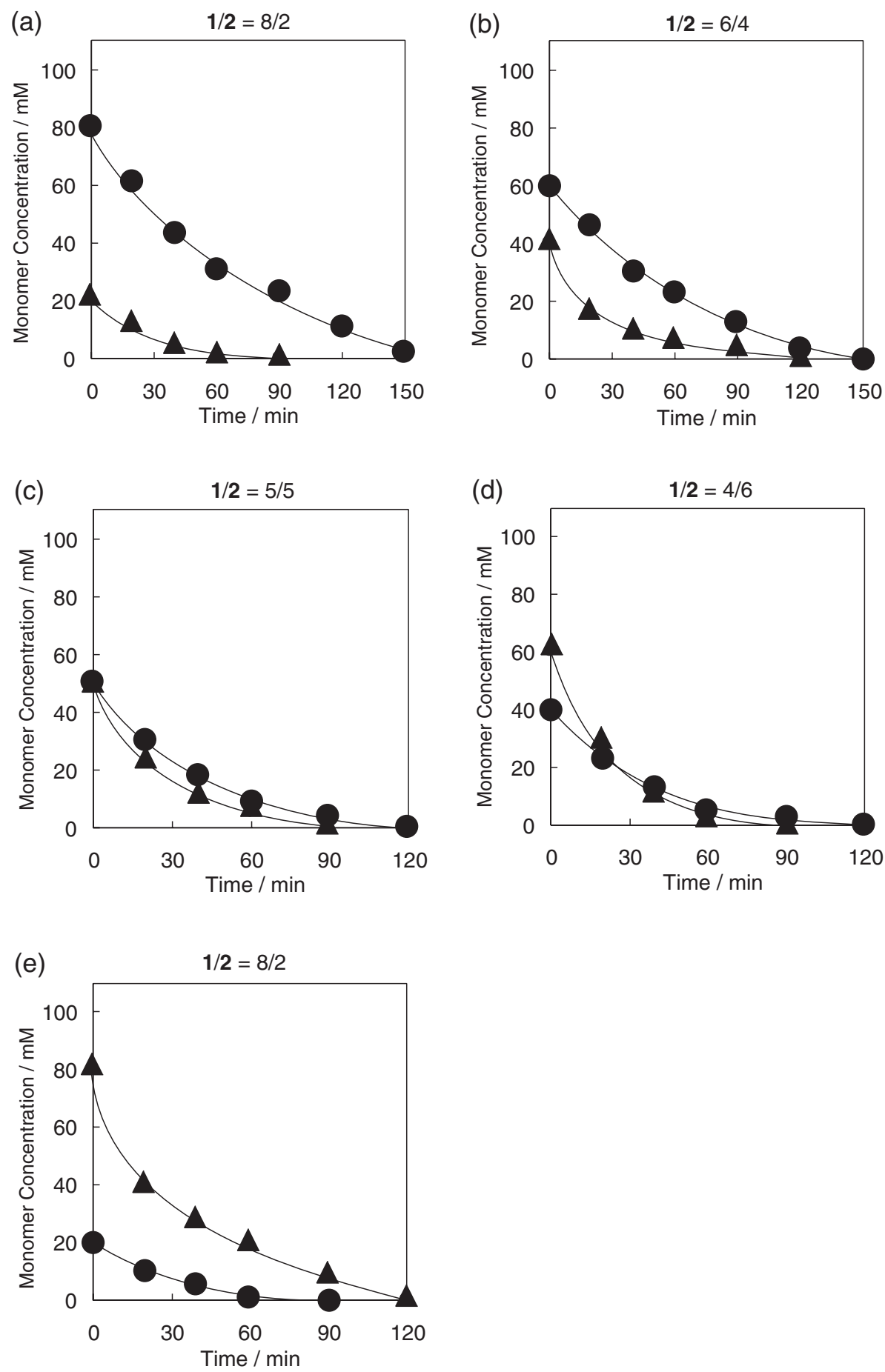

Figure 1. Reaction time-courses of comonomers $1(\bullet)$ and $2(\Delta)$.

subjected to Sephadex G-10 column chromatography eluting with distilled water. Then, the precipitate and the fractions containing 3 with molecular weight higher than that of tetrasaccharides were combined and lyophilized to give $\mathbf{3}$ ( $2.2 \mathrm{mg}, 58 \%$ isolated yield).

Determination of the Degree of $N$-Deacetylation (DDAc) in the Resulting Copolymer 3

It is reported that the ratio of the absorbance of the amide II band at $1550 \mathrm{~cm}^{-1}$ to that of the $\mathrm{C}-\mathrm{H}$ stretching band at $2878 \mathrm{~cm}^{-1}$ make a single linear relation- ship with the degree of $N$-deacetylation. ${ }^{18}$ IR measurements were carried out after adequate desiccation of the resulting product $\mathbf{3}$ under reduced pressure and DDAc of $\mathbf{3}$ was determined according to the literature reported. ${ }^{18}$

\section{RESULTS AND DISCUSSION}

Enzymatic Copolymerization of Monomers 1 and $\mathbf{2}$ Catalyzed by Chitinase from Bacillus $s p$.

Synthetic chitin was prepared from $N, N^{\prime}$-diacetyl- 


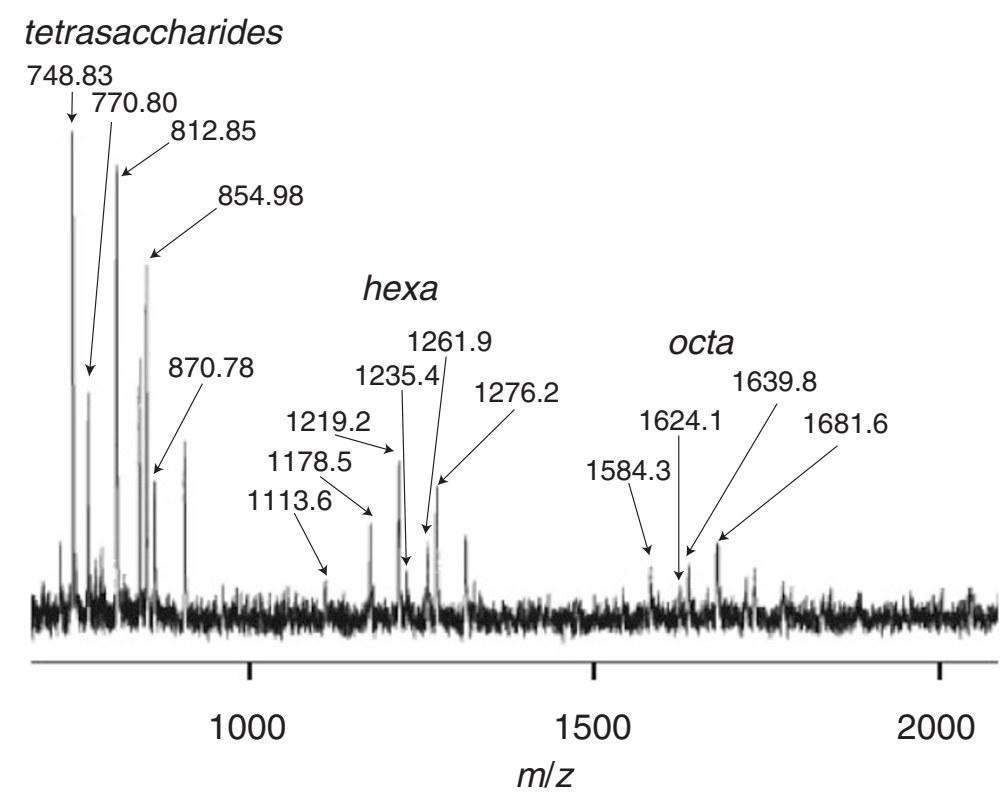

Figure 2. MALDI-TOF mass spectrum of the copolymer $\mathbf{3}$ (water-soluble part) obtained from the equimolar reaction of $\mathbf{1}$ and 2.

chitobiose oxazoline derivative (1) catalyzed by chitinase from Bacillus sp. ${ }^{15}$ Chitin-chitosan hybrid polysaccharide was also synthesized from $N$-acetylchitobiose oxazoline derivative (2) catalyzed by the same chitinase catalyst. ${ }^{17}$ Then, copolymerization between these monomers was examined using chitinase from Bacillus sp.

Comonomers 1 and 2 were mixed with $2: 8-8: 2$ $(\mathrm{mol} / \mathrm{mol})$ and dissolved in a $50 \mathrm{mM}$ phosphate buffer (pH 8.5) so as to become $100 \mathrm{mM}$ for the initial total concentration. To the solution kept at $10^{\circ} \mathrm{C}$, was added chitinase from Bacillus sp. $(5.0 \mathrm{wt} \%$ for the total comonomer concentration). The concentrations of $\mathbf{1}$ and 2 were monitored by HPLC. Figure 1 showed the reaction time-courses of each comonomer. Under the condition that the molar ratio of comonomers was $1: 1$, the consumptions of $\mathbf{1}$ and $\mathbf{2}$ were completed within $90 \mathrm{~min}$ and $120 \mathrm{~min}$, respectively. After $90 \mathrm{~min}$, more than $90 \%$ of comonomer $\mathbf{2}$ was consumed. Therefore, it is considered that the polymerizability of comonomer $\mathbf{1}$ is close to that of comonomer $\mathbf{2}$ and both comonomers were effectively catalyzed by chitinase. At the time that the consumption of either monomer was completed, the enzymatic reaction was stopped by heating the reaction mixtures at $90^{\circ} \mathrm{C}$ for $5 \mathrm{~min}$ so as to inactivate the enzyme catalyst.

As the enzymatic reaction progressed, white precipitate was produced. Then, the reaction mixture obtained after the termination of the enzymatic reaction was divided into the white precipitate and the supernatant by centrifugation. Figure 2 showed the mass spectrum of the supernatant measured by matrixassisted laser desorption ionization-time of flight mass spectrometry (MALDI-TOF/MS). On the spectrum,
Table I. Analytical data for MALDI-TOF mass spectrum of copolymer 3 given in Figure 2

\begin{tabular}{clc}
\hline saccharides & \multicolumn{1}{c}{$m / z$} & $\mathbf{1 / 2}$ unit ratio \\
\hline tetra $(4)$ & $748.83(+\mathrm{H})$ & $0 / 2$ \\
& $770.80(+\mathrm{Na})$ & \\
& $812.85(+\mathrm{Na})$ & $1 / 1$ \\
& $854.98(+\mathrm{Na})$ & $2 / 0$ \\
& $870.78(+\mathrm{K})$ & \\
hexa (6) & $1113.6(+\mathrm{H})$ & $0 / 3$ \\
& $1178.5(+\mathrm{Na})$ & $1 / 2$ \\
& $1219.2(+\mathrm{Na})$ & $2 / 1$ \\
& $1235.4(+\mathrm{K})$ & \\
& $1261.9(+\mathrm{Na})$ & $3 / 0$ \\
& $1276.2(+\mathrm{K})$ & \\
& $1584.3(+\mathrm{Na})$ & $2 / 2$ \\
& $1624.1(+\mathrm{Na})$ & $3 / 1$ \\
& $1639.8(+\mathrm{K})$ & \\
& $1681.6(+\mathrm{K})$ & $4 / 0$ \\
\hline
\end{tabular}

tetrasaccharides (dimer), hexasaccharides (trimer), and octasaccharides (tetramer) having the structural proportion of $\mathbf{1 / 2}$ ranging from $2 / 0$ to $0 / 2$, from $3 / 0$ to $0 / 3$, and from $4 / 0$ to $2 / 2$, respectively, were observed. The assignments of the peaks are given in Table I. There are some unassignable peaks, however, no peak derived from more than decasaccharides (pentamer) was detected. Chitin is hardly soluble in almost all solvents because of its high crystalline character, ${ }^{19}$ and chitooligosaccharides, more than octasaccharide, are hardly soluble in water. With exception, chitin derivatives having DDAc of 45$55 \%$ are soluble in water. In fact, the homopolymer of monomer 2, chitin-chitosan hybrid polysaccharide was soluble in water because its DDAc is $50 \%$. 


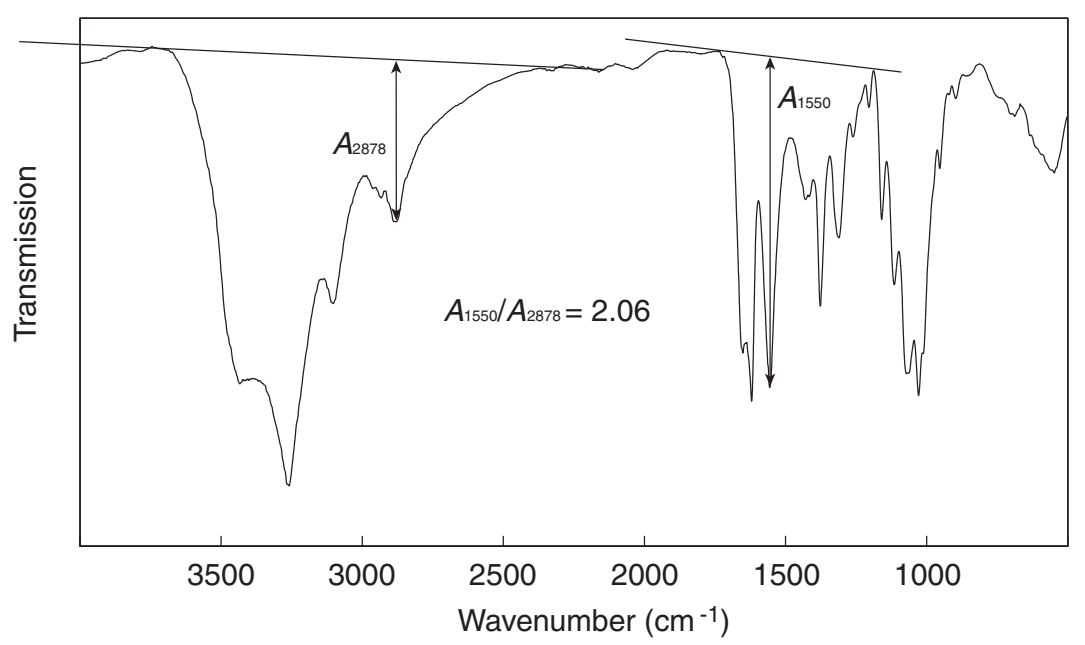

Figure 3. IR spectrum of copolymer 3, starting from the copolymerization with the monomer feed ratio 1:2 = 5:5, and baselines for determination of the peak absorbance.

At the homopolymerization of monomer 2, chitinchiotosan hybrid polysaccharide up to tetradecasaccharide (heptamer) was detected by MALDI-TOF/ MS. ${ }^{17}$ Under considering these results, copolymerization of $\mathbf{1}$ with $\mathbf{2}$ proceeded in a random fashion and more than octasaccharide (tetramer) is collected as white precipitates. Therefore, homopolymers of $\mathbf{2}$ were scarcely produced and in fact they were not detected by MALDI-TOF mass spectrometry from the supernatant.

In order to determine the DDAc of the resulting product, we used the method developed by Sannan et al. ${ }^{18}$ They found that the ratio of the absorbance of amino II band at $1550 \mathrm{~cm}^{-1}$ to that of the $\mathrm{C}-\mathrm{H}$ stretching band at $2878 \mathrm{~cm}^{-1}$ correlates with DDAc unidimensionality. Then, the resulting water-soluble product was purified with size exclusion chromatography (SEC) to remove the hydrolysates of comonomers and combined with water-insoluble products. The purified product was analyzed by IR measurement. Figure 3 indicates the IR spectrum of copolymer $\mathbf{3}$, starting the copolymerization with the monomer feed ratio $1: 2=5: 5(\mathrm{~mol} / \mathrm{mol})$. From the spectrum, the ratio of absorbance was calculated to be 2.06 and the DDAc of $\mathbf{3}$ was determined as 0.28.

The average molecular weight values of $\mathbf{3}$ and their DDAc were summarized in Table II. The DDAc values change closely with the comonomer feed ratio.

\section{Enzymatic Copolymerization of Monomers 1 and $\mathbf{2}$} Catalyzed by Chitinase from Serratia Marcescens

The reported chitinase species that catalyze the polymerization of $N, N^{\prime}$-diacetylchitobiose oxazoline derivative (1) effectively is only Bacillus sp. However, polymerization of $N$-acetylchitobiose oxazoline derivative (2) is catalyzed by chitinase from Serratia
Table II. Chitinase-catalyzed copolymerization under various conditions

\begin{tabular}{|c|c|c|c|c|c|c|}
\hline \multirow[b]{2}{*}{ entry } & \multicolumn{2}{|c|}{ polymerization $^{\mathrm{a}}$} & \multicolumn{4}{|c|}{ copolymer (3) } \\
\hline & $\begin{array}{c}\text { comonomer ratio } \\
\mathbf{1} / \mathbf{2}(\mathrm{mol} / \mathrm{mol})\end{array}$ & $\begin{array}{c}\operatorname{time}^{\mathrm{b}} \\
/ \mathrm{h}\end{array}$ & $\begin{array}{c}\text { yield }^{\mathrm{c}} \\
1 \%\end{array}$ & $\operatorname{DDAc}^{\mathrm{d}}$ & $M_{\mathrm{n}}^{\mathrm{e}}$ & $M_{\mathrm{w}}^{\mathrm{e}}$ \\
\hline 1 & $10 / 0$ & 3.0 & 60 & 0 & 1770 & 2090 \\
\hline 2 & $8 / 2$ & 1.5 & 42 & 0.10 & 1750 & 2140 \\
\hline 3 & $6 / 4$ & 2.0 & 56 & 0.22 & 1720 & 1880 \\
\hline 4 & $5 / 5$ & 1.5 & 58 & 0.28 & 1700 & 1890 \\
\hline 5 & $4 / 6$ & 1.5 & 58 & 0.33 & 1680 & 1840 \\
\hline 6 & $2 / 8$ & 1.5 & 51 & 0.45 & 1620 & 1700 \\
\hline 7 & $0 / 10$ & 3.0 & 58 & 0.50 & 1600 & 1730 \\
\hline
\end{tabular}

${ }^{\mathrm{a}}$ In $50 \mathrm{mM}$ phosphate buffer, Total concentration of $\mathbf{1}$ and $\mathbf{2}$ : $0.10 \mathrm{M}, \mathrm{pH} 8.5$, Reaction temperature: $10^{\circ} \mathrm{C}$, Enzyme: Chitinase from Bacillus sp. $5 \mathrm{wt} \%$ for the monomer. ${ }^{\mathrm{b}}$ Indicating the time that the consumption of either monomer is finished. ${ }^{c}$ Determined by SEC measurements containing products with molecular weight higher than tetrasaccharide. ${ }^{\mathrm{d}}$ Calculate from the comparative absorbance of amino II band $\left(1550 \mathrm{~cm}^{-1}\right)$ with $\mathrm{C}-\mathrm{H}$ stretching band $\left(2878 \mathrm{~cm}^{-1}\right)$. ${ }^{\mathrm{e}}$ Determined by SEC calibrated with chitooligosaccharide and pullulan standards.

marcescens, giving rise to the corresponding chitinchitosan hybrid polysaccharide. Therefore, we examined copolymerization of $\mathbf{1}$ with $\mathbf{2}$ using chitinase from Serratia marcescens as catalyst. Comonomers $\mathbf{1}$ and $\mathbf{2}$ were mixed with $1: 1(\mathrm{~mol} / \mathrm{mol})$ and dissolved in a $50 \mathrm{mM}$ phosphate buffer $(\mathrm{pH} 8.5)$ so as to become $100 \mathrm{mM}$ for initial total concentration. The chitinase was added to the reaction mixture for the amount of $5 \mathrm{wt} \%$ against the total amount of the comonomers. Figure 4 shows the reaction time-courses of the comonomers monitored by the HPLC analysis. The concentration of comonomer 2 was completed within $30 \mathrm{~h}$. Whereas, about $70 \%$ of comonomer 1 remained after $30 \mathrm{~h}$ and it took more than $168 \mathrm{~h}$ for the entire consumption. 


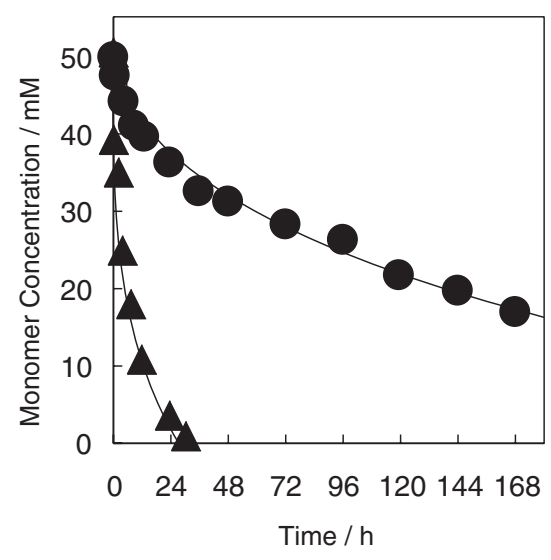

Figure 4. Reaction time courses of $\mathbf{1}(\bullet)$ and $\mathbf{2}(\mathbf{\Delta})$ catalyzed by chitinase from Serratia marcescens.

After $30 \mathrm{~h}$, the reaction mixture was divided into two sample tubes and one of them was heated at $90^{\circ} \mathrm{C}$ for $10 \mathrm{~min}$ to inactivate the enzyme catalysis. The reaction mixture was kept under homogeneous condition. After the purification of the reaction mixture using Sephadex G-10 column chromatography, the DDAc of the resulting product was calculated to be 0.41 (data not shown). The reactivity of $\mathbf{1}$ against $\mathbf{2}$ was greatly differed and homopolymerization of 2 mainly occurred during the first $30 \mathrm{~h}$. It has been reported recently that chitinase from Serratia marcescens also hydrolyze glycosidic bond of chitosan with DDAc $0.35-0.65 .{ }^{20}$ The hydrolysis rate of chitosan was accelerated with decreasing the amount of $\mathrm{N}$-acetyl group. Monomer $\mathbf{2}$ having an amino group is, therefore, a good substrate for the enzyme, leading to the smooth oxazoline ring-opening polyaddition.

\section{CONCLUSIONS}

The chitinase-catalyzed copolymerization of $N, N^{\prime}$ diacetylchitobiose oxazoline monomer (1) with $\mathrm{N}$ acetylchitobiose oxazoline monomer (2) was examined. The Bacillus sp. derived chitinase showed close polymerizability against comonomers $\mathbf{1}$ and $\mathbf{2}$, and catalyzed ring-opening copolyaddition. The DDAc of the resulting copolymers $\mathbf{3}$ could be controlled by the initial feed ratio of comonomers $\mathbf{1}$ and 2 . In contrast, chitinase from Serratia marcescens showed different catalytic activity against comonomers $\mathbf{1}$ and $\mathbf{2}$, and accelerated the ring-opening polyaddition of 2 faster than that of $\mathbf{1}$. As the result, copolymer $\mathbf{3}$ was hardly obtained.

The enzymatic copolymerization method permits the tailor-made synthesis of $N$-deacetylated chitin derivatives 3 with controlled number of amino functional groups.

\section{REFERENCES}

1. R. A. A. Muzzarelli, "Chitin," Pergamon Press, Oxford, U.K., 1977.

2. a) R. A. A. Muzzarelli and C. Muzzarelli, Adv. Polym. Sci., 186, 151 (2005).

b) M. N. V. R. Kumar, R. A. A. Muzzarelli, C. Muzzarelli, H. Sashiwa, and A. J. Domb, Chem. Rev., 104, 6017 (2004).

3. S. N. Chirkov, Appl. Biochem. Microbiol., 38, 1 (2002).

4. D. V. Gerasimenko, I. D. Avdienko, G. E. Bannikova, O. Yu. Zueva, and V. P. Varlamov, Appl. Biochem. Microbiol., 40, 253 (2004).

5. M. Ishihara, K. Nakanishi, K. Ono, M. Sato, M. Kikuchi, Y. Saito, H. Yura, T. Matsui, H. Hattori, M. Uenoyama, and A. Kurita, Biomaterials, 23, 833 (2002).

6. S.-K. Kim and N. Rajapakse, Carbohydr. Polym., 62, 357 (2005).

7. S. Şenel and S. J. McClure, Adv. Drug Delivery Rev., 56, 1467 (2004).

8. M. Ishihara, Trends Glycosci. Glycotechnol., 14, 331 (2002).

9. H. Sashiwa and S.-I. Aiba, Prog. Polym. Sci., 29, 887 (2004).

10. a) H. Merzendorfer and L. Zimoch, J. Exp. Biol., 206, 4393 (2003).

b) A. R. Yeager and N. S. Finney, J. Org. Chem., 69, 613 (2004).

11. D. Horton and D. R. Lineback, Methods Carbohydr. Chem., 5, 403 (1965).

12. a) R. V. S. Amorim, W. M. Ledingham, K. Fukushima, and G. M. Campos-Takaki, J. Ind. Microbiol. Biotechnol., 32, 19 (2005).

b) I. Tsigos, A. Martinou, D. Kafetzopoulos, and V. Bouriotis, Trends Biotechnol., 18, 305 (2000).

13. a) K. Nishimura, S.-I. Nishimura, N. Nishi, F. Numata, Y. Tone, S. Tokura, and I. Azuma, Vaccine, 3, 379 (1985).

b) K. Nishimura, S.-I. Nishimura, N. Nishi, I. Saiki, S. Tokura, and I. Azuma, Vaccine, 2, 93 (1984).

c) C. Qin, Y. Du, L. Xiao, Z. Li, and X. Gao, Int. J. Biol. Macromol., 31, 111 (2002).

14. a) S. Kobayashi and M. Ohmae, Adv. Polym. Sci., 194, 159 (2006).

b) S. Kobayashi, J. Polym. Sci., Part A: Polym. Chem., 43, 693 (2005).

c) S. Kobayashi, H. Uyama, and S. Kimura, Chem. Rev., 101, 3793 (2001).

d) S. Kobayashi, H. Uyama, and M. Ohmae, Bull. Chem. Soc. Jpn., 74, 613 (2001).

e) S. Kobayashi, J. Sakamoto, and S. Kimura, Prog. Polym. Sci., 26, 1525 (2001).

f) S. Kobayashi, J. Polym. Sci., Part A: Polym. Chem., 37, 3041 (1999).

g) S. Kobayashi, S.-I. Shoda, and H. Uyama, in "Catalysis in Precision Polymerization,” S. Kobayashi, Ed., John Wiley \& Sons, Chichester, 1997, chap. 8.

h) S. Kobayashi, S.-I. Shoda, and H. Uyama, Adv. Polym. Sci., 121, 1 (1995).

15. S. Kobayashi, T. Kiyosada, and S.-I. Shoda, J. Am. Chem. Soc., 118, 13113 (1996). 


\section{A. Makino, M. Ohmae, and S. Kobayashi}

16. H. Sato, S. Mizutani, S. Tsuge, H. Ohtani, K. Aoi, A. Takasu, M. Okada, S. Kobayashi, T. Kiyosada, and S.-I. Shoda, Anal. Chem., 70, 7 (1998).

17. A. Makino, K. Kurosaki, M. Ohmae, and S. Kobayashi, Biomacromolecules, 7, 950 (2006).

18. T. Sannan, K. Kurita, K. Ogura, and Y. Iwakura, Polymer,
19, 458 (1978).

19. M.-K. Jang, B.-G. Kong, Y.-I. Jeong, C. H. Lee, and J.-W. Nah, J. Polym. Sci., Part A: Polym. Chem., 42, 3423 (2004).

20. A. Sørbotten, S. J. Horn, V. G. H. Eijsink, and K. M. Vårum, FEBS J., 272, 538 (2005). 